\title{
Development of method for evaluating cell hardness and correlation between bacterial spore hardness and durability
}

\author{
Koichi Nakanishi ${ }^{*}$, Akinori Kogure ${ }^{2}$, Takenao Fujii ${ }^{3}$, Ryohei Kokawa ${ }^{3}$ and Keiji Deuchi ${ }^{1}$
}

\begin{abstract}
Background: Despite the availability of conventional devices for making single-cell manipulations, determining the hardness of a single cell remains difficult. Here, we consider the cell to be a linear elastic body and apply Young's modulus (modulus of elasticity), which is defined as the ratio of the repulsive force (stress) in response to the applied strain. In this new method, a scanning probe microscope (SPM) is operated with a cantilever in the "contact-and-push" mode, and the cantilever is applied to the cell surface over a set distance (applied strain).

Results: We determined the hardness of the following bacterial cells: Escherichia coli, Staphylococcus aureus, Pseudomonas aeruginosa, and five Bacillus spp. In log phase, these strains had a similar Young's modulus, but Bacillus spp. spores were significantly harder than the corresponding vegetative cells. There was a positive, linear correlation between the hardness of bacterial spores and heat or ultraviolet (UV) resistance.

Conclusions: Using this technique, the hardness of a single vegetative bacterial cell or spore could be determined based on Young's modulus. As an application of this technique, we demonstrated that the hardness of individual bacterial spores was directly proportional to heat and UV resistance, which are the conventional measures of physical durability. This technique allows the rapid and direct determination of spore durability and provides a valuable and innovative method for the evaluation of physical properties in the field of microbiology.
\end{abstract}

Keywords: Scanning probe microscope, Bacillus spp, Spore, Hardness, Young's modulus

\section{Background}

It is not easy to measure the physical properties of small cells, such as bacteria or organelles. Surface observations and physical measurements at the molecular and atomic level can be made using analytical instruments, particularly scanning probe microscopes (SPMs) [1]. Nonetheless, with some notable exceptions [2], there are very few methods for making direct physical measurements on individual cells. The physical property hardness is particularly informative of the characteristics of a cell, and much can be known about the cell from the determination of this parameter. Cell hardness is thought to be related to the resistance of bacterial spores to heat

\footnotetext{
* Correspondence: kouichi_nakanishi@kirin.co.jp

'Laboratory for Core Technology, Development Kirin Beverage Co, Ltd.,

Technovillage 3F, 1-17-1 Namamugi, Tsurumi-ku, Yokohama 230-8628, Japan Full list of author information is available at the end of the article
}

and UV. In the fields of food and pharmaceutical manufacturing, current methods for determining heat and UV resistance require viable cell counts involving cell culture and can take from a few days to 2 weeks or more to complete. There is a need for a non-cultivation method that can quickly yield results.

As there is no clear definition for the concept of hardness in biology, it is difficult to consider evaluation methods for the cell hardness. The cantilever used in an SPM is a type of spring. We developed a method using the cantilever probe of a SPM to determine the hardness of a cell, an organelle, or other microscopic specimen. Physical stress induced by contact of the probe with the specimen is used to determine the Young's modulus as a hardness parameter. Here, we report the evaluation of cell hardness for log phase cells and spores of bacteria and compare it to the heat and UV resistance. The relationship between hardness, given by Young's modulus,

\section{Biomed Central}


Table 1 Young' s modulus for vegetative cells and spores of bacteria

\begin{tabular}{lll}
\hline Bacterial strains & Vegetative cells & Spores \\
\hline S. aureus & $0.211 \pm 0.023$ & - \\
E. coli & $0.165 \pm 0.033$ & - \\
P. aeruginosa & $0.199 \pm 0.023$ & - \\
G. stearothermophilus & $0.222 \pm 0.041$ & $0.811 \pm 0.048$ \\
B. coagulans & $0.204 \pm 0.028$ & $0.682 \pm 0.039$ \\
B. subtilis & $0.215 \pm 0.018$ & $0.414 \pm 0.021$ \\
B. licheniformis & $0.233 \pm 0.034$ & $0.329 \pm 0.012$ \\
B. megaterium & $0.196 \pm 0.022$ & $0.240 \pm 0.059$ \\
\hline
\end{tabular}

Number of measurement samples $=10$.

Young's modulus, $\mathrm{E}(\mathrm{N} / \mathrm{m})=$ Physical stress of cell, $\sigma(\mathrm{nN}) /$ Applied strain of cell, $\epsilon(\mathrm{nm})$, where $\epsilon=50 \mathrm{~nm}$.

and spore characteristics can be used to evaluate spore durability in sporogenic bacteria.

\section{Results}

\section{Definition of hardness and measurement positions}

If hardness is expressed as the amount of work done for a given applied cantilever strain, that amount of work corresponds to a complex three-dimensional movement that would be difficult to measure accurately. However, the error factors are reduced if we limit this movement to the vertical direction along the $\mathrm{z}$-axis, as shown in Figure 1(A) and 1(B) and evaluate Young's modulus. In this way, the cell can be regarded as a linear-elastic body. The target sample is pressed by the cantilever with a fixed applied strain, $\epsilon$, and the repulsive force (stress), $\sigma$, $(\mathrm{N})$ is determined (Figure 1(B)). Hooke's law can be expressed as $\sigma=\mathrm{E} \epsilon$, where $E$ is Young's modulus $(\mathrm{N} / \mathrm{m})$ for log phase cells and spores, and is the physical stress arising in the cell due to the force exerted by the cantilever (depth of compression: $\mathrm{m}$ ). Hooke's law holds if the starting point (point a in Figure 1(B)) of the approach curve overlaps with the endpoint of the release curve for the cantilever (point b in Figure 1(B)). Young's modulus, E, was thus confirmed to be a parameter of cell hardness for various cells and spores $(\sigma / \epsilon)$. Young's modulus of the sample can thus be estimated within the range of the nano-probe evaluation with an identical spring constant.

Figure $1(\mathrm{C})$ shows a schematic diagram of taking measurements at the center and closer to the periphery of the cell. The SPM scans from the $\mathrm{z}$-axial direction, so evaluations made at the edge cannot be accurately measured. This means that it may not be possible to accurately measure physical stress in the peripheral regions. The diagram shows the forces from the sample when the measurement position is at the apex of both the $\mathrm{x}$ - and the $y$-axis, at a point slightly removed from the apex, and at the edge or at a point near the edge.

The relationship between hardness and point of measurement is shown for a representative spore specimen of Geobacillus stearothermophilus NBRC 13737 in Figure 2. Determination of Young's modulus every $40 \mathrm{~nm}$ along the $\mathrm{x}$ - and $\mathrm{y}$-axis shows that the most representative values for Young's modulus are obtained at the point where cell height is greatest along the $\mathrm{z}$-axis. Measurements made at points other than the maximum height are likely to include distributions of physical stress other than those along the $\mathrm{z}$-axis and will not accurately reflect Young's modulus along the z-axis. Furthermore, if measurements are made near the edge of the specimen, the Young's modulus measurement is likely to more reflect
(A)

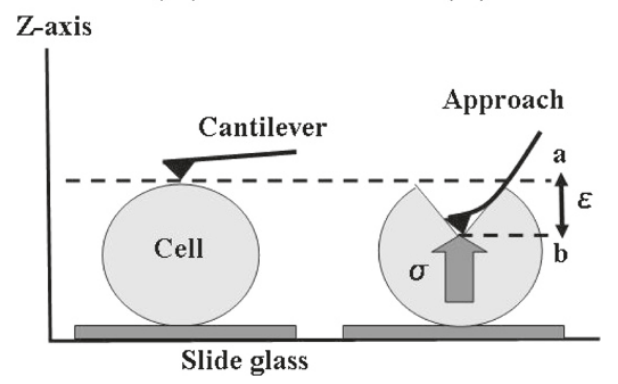

(C)

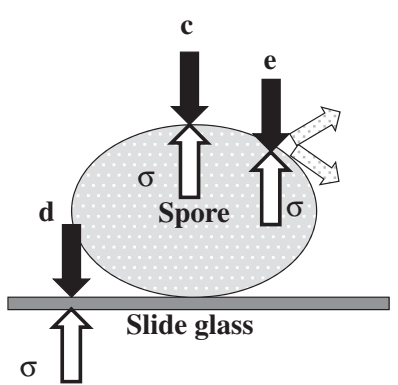

Figure 1 Principle for measuring cell and spore hardness using the cantilever of the SPM. (A) Position of the cantilever and cell before measurement. (B) Cantilever moves a fixed distance along the z-axis (measurement). a: Start position of cantilever, b: Position of cantilever after being depressed to apply strain to the cell, $€$ : Physical strain applied by the cantilever over a fixed distance (50 nm), $\sigma$ : cell physical stress (nN) (C) Diagram of physical stress states for various measurement positions. E: Young's modulus ( $\mathrm{N} / \mathrm{m}$ ); $\sigma$ : cell physical stress (nN); $\epsilon$ : physical strain applied by the cantilever $(\mathrm{nm})$ Young's modulus calculated by $\mathrm{E}=\sigma / \epsilon$. c: Stress in the cell can be accurately measured when the measurement position is the highest point along the $\mathrm{x}$ - and $\mathrm{y}$-axes, $\mathrm{d}$ : Stress from the slide glass is included in measurements taken at or near the edge of the cell, e: Stress is dispersed if measurement position is slightly away from the highest point. 

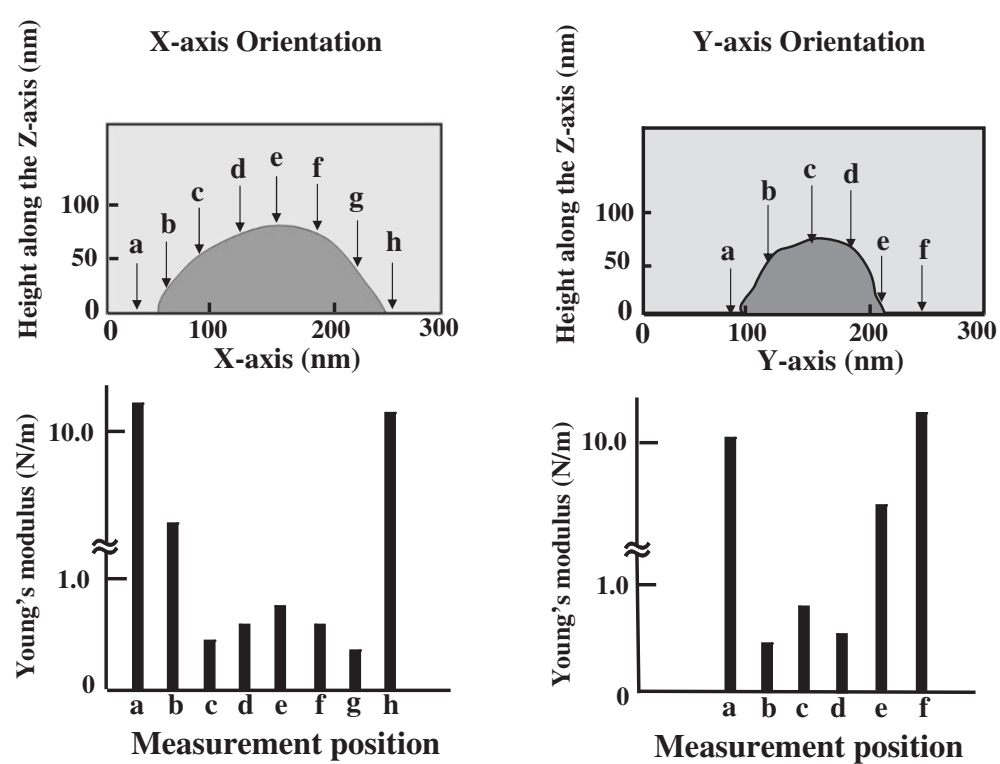

Figure 2 Representative measurement positions for G. stearothermophilus spore and determined Young's modulus. Upper slides showed the position to determination of Young's modulus every $40 \mathrm{~nm}$ along the $\mathrm{x}$ - and $\mathrm{y}$-axes. Small letters and arrows indicate measurement positions. Lower slides showed the results that Young's modulus was measured at $40 \mathrm{~nm}$ intervals along the $\mathrm{x}$ - and $\mathrm{y}$-axes. Letters indicate measurement positions of upper.

the hardness of the quartz glass slide than the hardness of the specimen.

Figure 3 shows the method for determining the measurement position with an SPM. First, G. stearothermophilus NBRC 13737 was taken as a sample specimen. Spore purity is confirmed to be $\geq 99 \%$ using a phasecontrast microscope, and the spore for measurement is selected (Figure 3(A)). Under a SPM, the measurement position of a single spore is determined as the intersection of the longitudinal $\mathrm{x}$-axis $\left(\mathrm{x}_{1}-x_{2}\right)$ and the minor $y$-axis $\left(y_{1}-y_{2}\right)$ as shown in Figure 3(B). The point of the maximum height measured on these cross-sections is used to set the indentation and measurement position for the cantilever and was used to determine the representative Young's modulus for the specimen.

\section{Young's modulus of cells and spores}

While there were only a small number of samples in the present study, for all bacteria strains tested, hardness of log phase cells was within a narrow range. While there were no clear differences in hardness between the five gram-positive bacteria strains (S. aureus, Geobacillus, and Bacillus spp.) and the two gram-negative strains (E. coli and $P$. aeruginosa), the gram-negative bacteria tended to have a lower Young's modulus. Further experiments using more strains of bacteria are needed to make more detailed examinations of differences between cells in $\log$ and stationary phases or for the use of different culture media. Further examination of additional bacteria species is needed to confirm this pattern. Generally, the greater hardness of spores than of vegetative cells
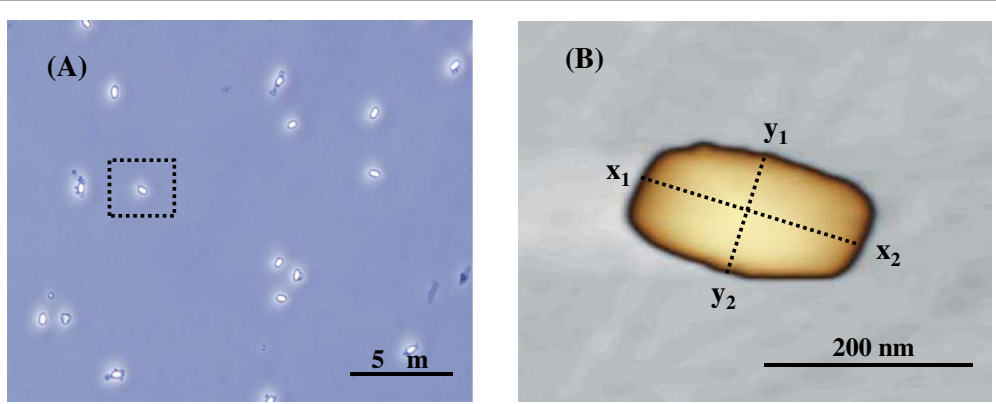

Figure 3 Measurement position for representative G. stearothermophilus strain spore. (A) Phase-contrast microscope image of spores under a phase-contrast microscope to confirm that the spore sample used for measurement has a purity of $\geq 99 \%$. (B) SPM image showing demarcation of $x$-axis $\left(x_{1}-x_{2}\right)$ and $y$-axis $\left(y_{1}-y_{2}\right)$ cross-sections of the spore. 
for a bacterial strain can be thought of as the basis for the durability of spores. However, while the spores of four Bacillus spp. other than B. megaterium were harder than the vegetative cells, there was no significant difference in hardness between the spores and vegetative cells for $B$. megaterium. This result may be due to the effect of the exosporium formed by $B$. megaterium, but this will need to be examined in future studies.

\section{Correlation between young's modulus and spore durability}

The comparison of spore durability and Young's modulus is shown in Figure 4. A plot of Young's modulus against an index of heat resistance, $\mathrm{D}_{121}$, or the time required to kill $90 \%$ of the viable bacteria by heating to $121^{\circ} \mathrm{C}$ shows a linear relationship $(\mathrm{r}=0.9811$, Figure 4 (A)). Similarly, Young's modulus plotted against an index of UV resistance, irradiation energy, or the product of irradiation intensity and irradiation time at which $10 \%$ of bacteria survive shows a linear relationship $(r=0.9751$, Figure 4(B)).

\section{Discussion}

Greater cell hardness for spores than for vegetative cell of sporulating bacteria can be assumed to confer greater physical durability, such as heat resistance to spores. A number of different hypotheses for the formation of more durable spores have been proposed. Setlow [3] attributed the high physical durability of spores primarily to the low water content in the core of the spore, which is due to compression and dehydration during spore cortex formation processes. Porham et al. [4] proposed dehydration within the spore core as the major factor. Paredes-Sabja et al. [5] hypothesized that minute structures composed of dipicolinic acid (DPA) with a dehydration function in the core of the spore were responsible for the increased durability. Grehardt et al. [6] reported that for Bacillus spp., lower water content within the spore was correlated with higher durability and that positive correlations were seen between the water content and each thermal processing $\mathrm{D}$ value. Taken together, increased hardness resulting from reduced water content in the spore is related to durability.

In particular, hardness is thought to be acquired due to the dehydrating effect of the formation of bonds between dipicolinic acid, which is a unique component of spores, and calcium. The dehydrated spore has a strong and resilient structural hardness that confers strong physical durability. The difference in hardness between vegetative cells and spores of sporulating bacteria and the strong correlation between hardness and heat and UV resistance of the spores support this hypothesis.

Further work is required to expand this method to other applications. A first step to understanding the applicability of this method is to investigate additional spore specimens. While a correlation was found between hardness and durability in the present study, a spore with high cell hardness is not necessarily UV resistant. Nicholson et al. [7] noted the relationship between heat resistance and divalent metal ions and the involvement of DNA repair enzymes in UV resistance. These enzymes have a direct relationship to the resistance mechanism, and it is likely that bacteria that form harder spores have higher divalent metal ion concentration and DNA repair enzyme production. The mechanism of spore durability is not yet fully clarified, but the present study offers some new and relevant findings. More heat- and UV-resistant mutants will need to be studied to clarify whether the

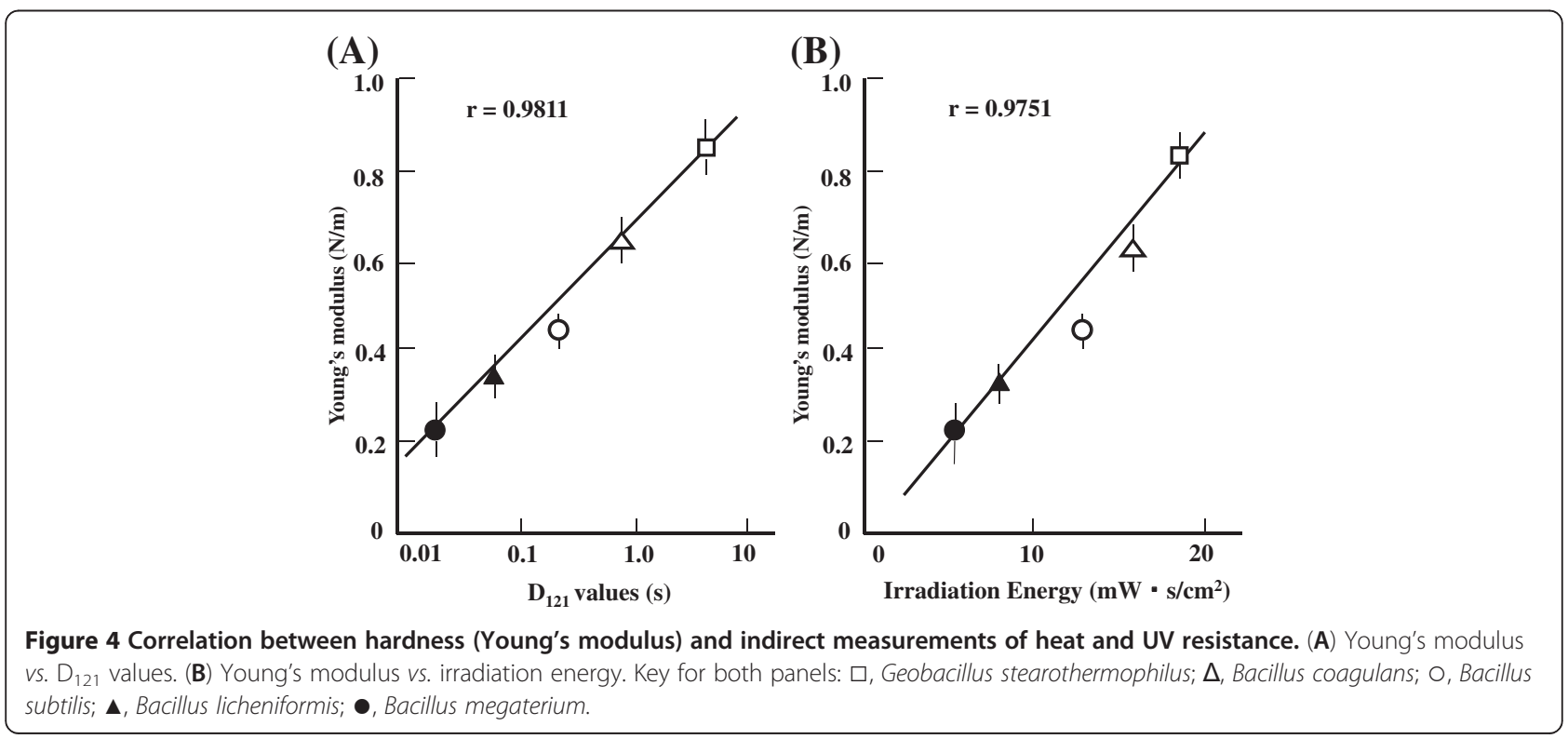


correlations observed in the present study are direct correlations or whether they indicate indirect agreement. Also, in addition to dehydration of the spore, it is likely that differences in the spore coat contribute to differences in hardness; spore coat deletion variants will make it possible to investigate the correlation between hardness and durability in greater detail. The correlations between spore hardness and heat and UV resistance observed in the present study should be tested using alternative methods for measuring hardness. We expect that this new analytical method can be used to directly measure hardness on any type of cell and will have applications in a wide range of research, including pharmaceutical and food product testing.

\section{Conclusions}

We developed methods to directly measure the physical properties of a single cell using bacterial spores and a SPM. The hardness of a single cell is described in terms of its Young's modulus. Using this technique, the hardness of bacterial cells could be measured for the first time. We used this technique to measure the hardness of individual spores of spore-forming bacteria strains and observed a high correlation between spore hardness and resistance to heat and UV, which are conventional measures of physical durability. The present technique will permit the rapid measurement of spore durability and will be a powerful tool for clarifying its mechanisms. Most importantly, this technique allows the physical evaluation of a single spore, which may lead to breakthroughs in the field of microbiology.

\section{Methods}

\section{Bacterial strains}

For hardness measurements, five Bacillus spp. with different heat resistances and typical gram-positive and gram-negative bacteria were selected from the ThermoKill Database R8100 [8]. Vegetative cells of three strains of "non-sporulating" bacteria were used: Staphylococcus aureus subsp. aureus NBRC 100910, Escherichia coli IFO 3301 and Pseudomonas aeruginosa ATCC 10145. Vegetative cells and spores of the following sporulating Bacillus spp. and related genera were used: Geobacillus stearothermophilus NBRC 13737, Bacillus coagulans DSM 1, B. subtilis NBRC 13719 T, B. megaterium NBRC $15308 \mathrm{~T}$ and B. licheniformis NBRC 12200.

\section{Culture and pretreatment methods}

All test bacterial strains were cultured in Difco nutrient broth at $35^{\circ} \mathrm{C}$, except for G. stearothermophilus, which was cultured at $60^{\circ} \mathrm{C}$. The vegetative cells were used for experiments after they were confirmed to be in log phase $\left(\mathrm{OD}_{600}=0.8-1.0\right)$ at 4 to $12 \mathrm{~h}$ after inoculation. Sporeforming Bacillus spp. were examined by phase-contrast microscopy to ensure that no spores were present before being used as vegetative cells in experiments. Bacterial log phase cells were prepared for hardness evaluation by centrifuging at $8,000 \times g$, washing the pellet with pure water, mounting cells on quartz slide glass, and drying. Samples were taken prior to the washing step to evaluate the effects of washing with pure water on viable cell count. Bacillus spp. spores were collected from 96-h cultures and were prepared for analysis in the same manner as the vegetative cells following resuspension in lysozyme $(10 \mathrm{mg} / \mathrm{ml})$ in $10 \mathrm{mM}$ Tris-HCl buffer and centrifugation at $8,000 \times g$ to remove vegetative cells. The prepared spore suspensions were examined by phase-contrast microscopy to confirm that $\geq 99 \%$ of the spores were mature before use in experiments.

\section{Hardness measurement method (young's modulus)}

With the exception of long rod-shaped bacteria, the shape of bacterial cells is close to spheroidal, and the size is in the range of 0.1 to several micrometers ( $\mathrm{z}$-axis length of 0.1 to $1 \mu \mathrm{m}$ ). To make the hardness evaluation, assumptions were made that bacterial cells are limited in size and behave as linear-elastic bodies. For hardness determination of each strain, 10 cells of similar shape and size were selected for analysis, and the mean of the measurements was calculated.

The hardness of the cells was evaluated with an SPM equipped with a Nano Search Microscope (SFT-3500, Shimadzu Corporation). The cantilever probe (Olympus, OMCL-AC240TS) was pressed against the surface of a cell with a physical strain assumed to be $\epsilon=50 \mathrm{~nm}$, the repulsive force, $\sigma(\mathrm{nN})$ was measured, and these two values were used to calculate Young's modulus E (N/ $\mathrm{m})=\sigma / \epsilon$.

Taking into account that measurements are performed on live samples, probes with a light spring constant of $\mathrm{k}=2 \mathrm{~N} / \mathrm{m}$ were used to make hardness measurements. To avoid the effects of interlot variation, each set of comparative tests was carried out with probes from a single lot.

\section{Heat and UV resistance}

$D_{121}$ values, or the time required to kill $90 \%$ of viable bacteria with heating to $121^{\circ} \mathrm{C}$, for samples cultured in $\mathrm{M} / 15$ phosphate buffer ( $\mathrm{pH} 7.0)$ and heated in thermal death time (TDT) tubes [9] were obtained from the ThermoKiLL Database R8100 [8]. The $\mathrm{D}_{121}$ value for each Bacillus spp. was used as the heat resistance parameter. For UV resistance, the UV exposure (mW-sec/ $\mathrm{cm}^{2}$ ) required to kill $90 \%$ of the bacteria was determined. Spore suspensions at $10^{5} \mathrm{CFU} / \mathrm{ml}$ in pure water were placed at a depth of $5 \mathrm{~mm}$ in a $90 \mathrm{~mm}$ Petri dish and irradiated at an intensity of $0.3 \mathrm{~mW} / \mathrm{cm}^{2}$ using a GLQ lamp (15 W, UVC of mainly $185 \mathrm{~nm}$, Toshiba 
Lighting \& Technology Corporation) placed at a distance of $10 \mathrm{~cm}$. Viable bacteria counts were taken every $10 \mathrm{~min}$ for $60 \mathrm{~min}[10,11]$.

\section{Competing interests}

The authors declare that they have no competing interests.

\section{Acknowledgements}

We would like to thank Dr. Hiromu Takamatsu, Dr. Ritsuko Kuwana, Dr. Daisuke Imamura and Prof. Kazuhito Watabe of Setsunan University's Faculty of Pharmaceutical Sciences for their invaluable advice.

\section{Author details}

${ }^{1}$ Laboratory for Core Technology, Development Kirin Beverage Co, Ltd., Technovillage 3F, 1-17-1 Namamugi, Tsurumi-ku, Yokohama 230-8628, Japan. ${ }^{2}$ Shimadzu Analytical \& Measuring Centre, Inc, 380-1 Horiyamashita, Hatano, Kanagawa 259-1304, Japan. ${ }^{3}$ Analytical \& Measuring Instrument Division, Shimadzu Corp, 1 Nishinokyo Kuwabara-cho, Nakagyo-ku, Kyoto 604-8511, Japan.

\section{Authors' contributions}

KN designed experiments, analyzed data, and prepared the manuscript. AK, TF, and RK developed and supervised the use of the Nano Search microscope SFT-3500 for microbiological research. KD supervised experiments. All authors discussed the results and commented on the manuscript. All authors read and approved the final manuscript.

Received: 29 November 2011 Accepted: 7 June 2012

Published: 7 June 2012

\section{References}

1. Sugimoto Y, Pablo P, Abe M, Jelinek P, Perez R, Morita S, Custance O: Chemical identification of individual surface atoms by atomic force microscopy. Nature 2007, 446:64-67.

2. Michel JP, Ivanonska IL, Gibbons MM, Klug WS, Knobler CM, Wuite JL, Schmit CF: Nanoindentation studies of full and empty viral capsids and the effects of capsid protein mutations on elasticity and strength. PNAS 2006, 103:6184-6189.

3. Setlow P: Spore of Bacillus subtilis: their resistance to and killing by radiation, heat and chemicals. J. Appl. Microbiol. 2006, 101:514-525.

4. Porham DL: The Bacillus subtilis dac $B$ gene, encoding penicillin-binding protein $5^{*}$, is part of a three-gene operon required for proper spore cortex synthesis and spore core dehydration. J. Bacteriol. 1995, 177:4721-4729.

5. Paredes-Sabja D, Setlow B, Setlow P, Sarker MR: Characterization of Clostridium perfringens spores that lack Spo VA proteins and dipicolinic acid. J. Bacteriol. 2008, 190:4648-4659.

6. Gerhardt P, Marquis RE: Spore thermoresistance mechanism. In Regulation of Prokaryotic Development. Edited by Smith I, et al. Washington, D.C., USA: American Society for Microbiology; 1989:43-63.

7. Nicholson WL, Murakata N, Horneck G, Melosh HJ, Setlow P: Resistance of Bacillus endospores to extreme terrestrial and extraterrestrial environments. Microbiol. Mol. Biol. Rev. 2000, 64:548-572.

8. TriBiox Laboratories: ThermoKill Database R8100, Ver. 3. Kyoto Japan: TriBiox Laboratories; 2006.

9. Stumbo CR: Thermobacteriology in Food Processing. 2nd edition. Orlando, FL, USA: Academic: 1973.

10. BPC, Inc: Sterilization by intense ultra-violet radiation. Oklahoma City, OK, USA: BPC Technical Report, BPC Inc; 1980:8.

11. TANA: UltraViolet Radiation, Native halamed-He Industry. TANA Technical Report 1982:7.

doi:10.1186/1477-3155-10-22

Cite this article as: Nakanishi et al.: Development of method for evaluating cell hardness and correlation between bacterial spore hardness and durability. Journal of Nanobiotechnology 2012 10:22.

\section{Submit your next manuscript to BioMed Central and take full advantage of:}

- Convenient online submission

- Thorough peer review

- No space constraints or color figure charges

- Immediate publication on acceptance

- Inclusion in PubMed, CAS, Scopus and Google Scholar

- Research which is freely available for redistribution

Submit your manuscript at www.biomedcentral.com/submit 